\title{
Science and Technology of Everyday Life: A course in technology for liberal arts students
}

\author{
John Krupczak, Jr, \\ Hope College
}

\begin{abstract}
A course in technological literacy has been developed and implemented at Hope College. The course is intended for the general education of liberal arts students The objective is to develop a familiarity with how various Technological devices work, and to explain the basic scientific principles underlying their operation. Topics covered include: the automobile, radio and television, computers, and medical imaging. The format is three hours of lecture and three hours of laboratory per week over a 15 week semester. The course was first offered in the Spring 1995 semester. The target audience for the course was seen as general liberal arts students. A major goal of the course is to reduce the fear and apprehension of this group toward understanding technology. The course focuses on the wide variety of technology used in everyday life to help in engaging the student's interest. The lecture portion of the course is taught in a single section by one member of the engineering faculty. Student attitudes generally support the conjecture that a course based on familiar technology would be a suitable motivation for student interest, enrollment has increased to a maximum capacity of 50 students.
\end{abstract}

\section{Introduction}

Modern societies depend upon technological devices for communication, food production, transportation, health care, and even entertainment. While the dependence on technology is widely recognized, very few students receive any formal education in technology. In an undergraduate education, engineering students, students in some of the sciences such as physics, and possibly vocational students, receive an exposure to the complexities and workings of technology. The majority of liberal arts students receive no education in technology despite fulfillment of college graduation requirements which include science courses.

One of the causes for this lack of exposure can by identified by noticing that the current route to understanding technology requires liberal arts students to minor or double major in a science such as physics or a branch of engineering. Introductory courses in the sciences generally do not focus on technological applications. A need exists for a one semester course through which liberal arts students might gain an understanding of technology sufficient for their future life experience and careers.

In this paper the development of a course in technology specifically for liberal arts students is reported. The target audience is described, and the goals and objectives are outlined. The means of implementation and the results of two semesters experience are given.

\section{Course Audience}

The students for whom the course is intended are general liberal arts students. The course described draws students with business, education, fine arts, languages, humanities, and social sciences majors. These

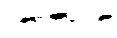


individuals are consumers of technology not its producers. The course is intended to fulfill part of the college general education requirements.

An attempt was made to characterize the target audience. While the methods used were not rigorous, surveys-and interviews provided a sense of the attitudes of the target audience. Results showed this group to have generally negative attitudes about their ability to understand science and technology. The group is further characterized by a limited experience in the use of tools, limited experience in making things (informal engineering ), and a limited experience troubleshooting, debugging, or fixing technological devices. The students are however, interested in something they perceive as practical and useful. Students appear to define practical to be as an understanding of the things they use everyday, or information perceived as directly applicable to their career choice. The students generally have an interest in knowing more about technology, but there are limits to how far they are willing, or able, to go on their own to pursue that interest.

\section{Objectives in Course Development}

The main objective was to create a course that would appeal to student interests and overcome their negative attitudes about understanding science and technology. The class was envisioned as a broad-based survey course of technology in the same sense of art, history, or music survey courses. The course was to provide students with an understanding of major technologies and related scientific concepts at level appropriate to their projected career path. Considering the evolving nature of technology, one other objective was to establish the student's ability to find and understand scientific and technological information without outside assistance.

Other objectives were an emphasis on hands-on experience. Some experience should be gained in use of tools, building things, and making things work. As much as possible, students should have exposure to the workings of actual technological devices of which they were previously only consumers.

The target class size of $\mathbf{3 6}$ students. The course was to utilize typical equipment already available to a liberal arts physics or engineering department. In the case of Hope College, it was expected that the class would be taught by one faculty member from the Department of Physics and Engineering.

\section{Course Description}

The format that has been developed is a 4 credit lecture and laboratory course for one 15 week semester. There are 3 hours of lecture and one 3 hour laboratory per week. The lecture includes demonstrations and some short hands-on activities. Laboratories are used for more involved experiential learning activities.

The guiding perspective in implementation is that the structure of the course should be designed for the specific needs of the target audience and not a simplified version of an introductory physics course for engineering and physics majors. It is assumed that the students have no prior technical knowledge or hands-on experience. As in any survey course, compromises had to be made between the number of topics covered and the depth of the material presented. In general, the focus is on technology, and concepts from basic science are introduced as they appear in the context of technology rather than vice versa.

The book used as a text is The Way Things Work, by David Macaulay'. The book is not a traditional textbook and this fact seems to help establish a good attitude on the part of the students. Supplementary readings are taken from a variety of sources including: Crouse and Anglin ${ }^{2}$, Wilson ${ }^{3}$ and Griffith ${ }^{4}$.

\section{Course Topics}

The topics studied were selected to represent the technology most frequently encountered in everyday life and were based partly on the results of surveys of student interests. The order of coverage is a compromise between organization based on technological applications, organization based on the underlying scientific , 
principles, and organization based on the classification scheme employed in Macaulay 1 . The presentation of most topics includes some historical information related to the invention and development of the technology. -

\section{Automobile}

The automobile is described as a group of interconnected systems, each performing a particular function. The systems classifications used are: engine, fuel and air, exhaust, cooling, lubrication, power train, brakes, steering, suspension, and electrical. The components associated with each system and their interrelations are described. Common problems and their symptoms are discussed. The internal combustion engine as the key component in the automobile is examined in detail. The four-stroke cycle and the functioning of engine components is described. Lectures utilize demonstrations with automobile components and service diagrams. In the associated laboratory, students working in pairs disassemble and reassemble 4-cylinder automobile engines.

In the automobile section, the amount of basic science introduced is small. The emphasis is on getting students with little technical background to become experienced in thinking through the cause and effect relationship involved in mechanical systems. The engine laboratory begins developing hands-on experience and creates a sense of familiarity with actual automobile components. Student reaction to the automotive section has been positive. The level of student interest is high and this section helps to establish momentum for the course.

\section{Basic Electrical and Magnetic Devices}

The next segment of the course begins to discuss technological devices which are based on the applications of electricity and magnetism. Discussion starts with a description of the atomic theory of matter and proceeds to electrostatics including coulombs law, electrostatic charging, voltage, and the concept of the electric field. The photocopier is discussed as an application of static electricity.

The next topics covered relate to electric current: the concepts of current, resistance, the difference between alternating and direct current, and ohm's law, and joule heating. Devices discussed in this section are: batteries, house wiring, and electrical safety. A laboratory involving basic electrical measurements is used to improve familiarity with concepts of voltage, current, electrical circuits, and frequency.

Basic concepts of magnetism, magnetic materials, the magnetic field, electromagnets, and magnetic forces on moving electric charges are described. Motors are described and students build a motor in a laboratory project. Discussion then focuses on electromagnetic induction. This concept is vital to the understanding of many consumer products, and is perhaps one of the most difficult concepts for students in the course. After induction is described, students are able to understand how electric generators and transformers work. Utility power generation and transmission are described, and a field trip is taken to a local power plant.

Except for the extended discussions of the photocopier, motors, and power generation, the electricity and magnetism section just described is very similar to that which would be found in a conceptual physics course. To maintain student interest, it appears that the course must emphasize practical technological applications rather than basic science. The student attitudes demand to see the application first before attempting to understand the science. However, unlike the automobile, understanding the wide variety of technology based on electricity and magnetism requires mastery of a body of scientific concepts. In this section, the development of the scientific ideas determines the order in which particular technological devices are examined. Once the basic science of electricity and magnetism has been addressed, the character of the course resumes a more technologically-oriented perspective.

\section{Light. Lenses. and Electromagnetic Waves}

Topics next covered are generation of incandescent, fluorescent, and laser light. The science of electromagnetic waves is explained. The electromagnetic frequency spectrum is described. The relationship between wavelength and frequency is discussed, and, in the visible range, the relationship between color and 
wavelength is explained. Basic concepts are followed by a discussion of light propagation, lenses, the eye, and corrective glasses:-The basic principles of black and white and color film and developing are explained. The : workings of the single lens reflex camera are described. In a laboratory, students build and operate a pinhole camera. ...

\section{$\underline{\text { Sound and Consumer Audio }}$}

Basic concepts of sound such as the relationship between sound and vibration, frequency and pitch, intensity, complex waveforms, and human hearing are described. A laboratory is used to illustrate these principles. This material provides the background needed to understand consumer audio electronics.

Performance features of the audio amplifier are explained. The working of transistors and their central role as amplifiers is described. Speakers are explained as an application of electromagnetism. The principle of analog recording of sound is described. The function of the key components such as the recording heads is explained. The importance of electromagnetic induction in the recording process is emphasized.

Disassembled tape recorders are used to identify the major components. The mechanics of the compact disk and disk player are described. The concept of digital representation of the audio signal, and the use of binary numbers is explained. Issues related to sampling frequency and the needed for error correction are examined.

\section{Telecomm unications}

The telephone, radio, and the television, are described under the classification of telecommunications. The term telecommunications is used to classify a variety of technologies which transmit information as electric current or electromagnetic waves. Basic concepts of electricity and magnetism have already been described, so the explanations focus on the engineering aspects of these devices.

The key step of conversion of sound into an electric current in the telephone is described. The functioning of a basic electromagnetic microphone is explained. Telephony is characterized as a process of first converting sound into electricity, transmission via an electric current, and then conversion of electric current back into sound. Switching networks and the dialing process are explained. In a laboratory project, students disassemble and then reassemble telephones to identify the major components. The electromagnetic microphones are extracted and used to create simple person-to-person telephones.

Radio is discussed, starting with the underlying science of electromagnetic waves, the concept of encoding information in either amplitude or frequency modulation on a carrier wave is explained. In laboratory, each student builds a simple crystal radio which develops familiarity with the basic components of the antenna, inductor, and diode.

The explanation of the television centers on the functioning of the picture tube. The basic process of creating an image by moving an electron beam across the phosphor screen using a magnetic field is explained. Color TV using three electrons beams for the primary colors of red, green, and blue is also described. Demonstrations utilize disassembled television components.

\section{$\underline{\text { Computers }}$}

The topic of computers is so broad that the treatment must be highly selective. In this course emphasis is placed on understanding basic aspects of computer hardware rather than developing experience with using any particular type of software. Binary numbers and ASCII code are explained. Boolean functions are introduced to the point that it is possible to describe the functioning of a four bit full adder. The remainder of the section describes the function and working of major the computer components of the processor, memory, storage devices, and communication. The descriptions are aimed at making it possible for students to interpret the information given in advertisements for personal computer systems. An overview of the intemet and computer networks is included. 
Medical imaging, refrigeration and air conditioning, microwave ovens, and heavier-than-air flight are products engineering which are part of the common technological experience. The course addresses these topics, in some cases introducing new scientific concepts, and in others relying on previous explanations of electromagnetic phenomena. During this period the laboratory experience involves the construction of a simple electronic keyboard using an integrated circuit.

\section{Assessment and Grading}

Grading and student assessment are based on papers, quizzes, laboratory reports, homework assignments, and participation in class activities. Quizzes emphasize knowledge of basic concepts, explanations of underlying science, and familiarity with relevant terminology. Students write three short papers of 3 to 5 pages, and one final term paper of 8 to 10 pages. A primary purpose of the papers is to develop the ability of the student to be self-educating in scientific and technical topics. For the final paper students must select a technological issue not previously covered in class and demonstrate a capacity for independent thinking and synthesis of information.

\section{Results and Conclusions}

This course has been taught at Hope College in the spring and fall 1995, and spring 1996 semesters. For the spring 1996 offering the enrollment increased to the maximum capacity of 50 with an additional 20 students on a waiting list. Enrollment included students with majors such as: art, business, psychology, languages, and education. From these trends it appears that this type of course appeals to the interests and needs of non-science and non-engineering students.

\section{Future Work}

A basic format that is suitable for liberal arts students has been established. Currently efforts are aimed at increasing the depth of coverage of material and improved assesment. Organizational methods which would maximize the number of students served with a fixed amount faculty and staff time are under investigation.

\section{Acknowledgments}

This work was supported by Hope College through the Department of Physics and Engineering, the Natural Sciences Division, and the Matthew J. and Anne C. Wilson Foundation. Helpful contributions were made: Catherine Brooks, Paul DeYoung, Peter Jolivette, Kevin Gardner, Carl Luchies, Catherine Mader, Peter Mills, Brad Mulder, Sueann Nieuwbeerta, Ned Rouze, Darryl Thelen, and Jim vanPutten.

\section{References}

Macaulay, D., The Way Things Work, Houghton Mifflin Company, (1988).

2. Crouse, W. H. and Anglin, D. L., Automotive Mechanics, McGraw-Hill, (1993),

3. Wilson, J. D., Physics, Saunders, (1993),

4. $\quad$ Griffith, W. T., Physics of Everyday Phenomena, Wm. C. Brown, (1992).

\section{JOHN KRUPCZAK, JR.}

John Krupczak is a Visiting Assistant Professor of Engineering at Hope College in Holland, Michigan. He has an undergraduate degree in physics from Williams College ( 1980) and a Ph.D. degree in mechanical engineering from the Unversity of Massachusetts at Amherst (1994). He has worked for GTE Inc., and at the Superconducting Super Collider Laboratory in Dallas, Texas. His email address is: krupczak@hope.edu. 